1 Grode, G A, et al, Transactions: American Society for Artificial Internal Organs, 1969, 15, 1.

${ }^{2}$ Lagergren, H R, and Eriksson, J C, Transactions: American Society for Artificial Internal Organs, 1971, 17, 10.

${ }^{3}$ Stewart, R D, and Sanislow, C A, New England fournal of Medicine, 1961, 265, 1283.

4 Hoshal, V L, Archives of Surgery, 1975, 110, 644.

5 Welch, G W, et al, Surgery, Gymecology and Obstetrics, 1974, 136, 421.

(Accepted 22 August 1979)

Gastroenterology Department, St Bartholomew's Hospital, London EC1A 7BE

M J G FARTHING, BSC, MRCP, honorary lecturer

ANNA M MATTEI, MD, research assistant

\section{Methodical variation of subcutaneous insulin injection sites}

The desirability of frequently varying the site of subcutaneous insulin injection in insulin-dependent diabetics has been widely accepted for many years, thus making less likely the local complications of subcutaneous fat atrophy, fatty tumour formation, and irritation at the injection site. ${ }^{1}$ The upper and outer aspects of the thighs usually bear the brunt of any rotational injection regimen because of their accessibility.

We describe here a simple scheme of methodical injection-site variation around the upper thighs used by one of us (JOM), an insulin-dependent diabetic of 20 years' standing. Over this lengthy period no particular local complications have been encountered.

\section{Method}

A flexible grid is obtained by cutting in half longitudinally a plastic Addis sink mat obtainable from any hardware store. This provides a 96-square grid in which each square covers an area of about $2 \cdot 25 \mathrm{~cm}^{2}$. Lettering the grid along its length and numbering across its breadth produces a template in which each individual square is identified Thus theoretically there are 96 injection sites on the upper and outer aspects of each thigh, amounting to 192 injection sites over both thighs.

The patient sits with his thighs flexed to $90^{\circ}$. The grid is placed lengthwise on the upper and outer aspects of the thigh, with its medial longitudinal border (AB) in line with the middle of the patella (C) (see figure). Consistent positioning can be obtained by always placing the lower border of the
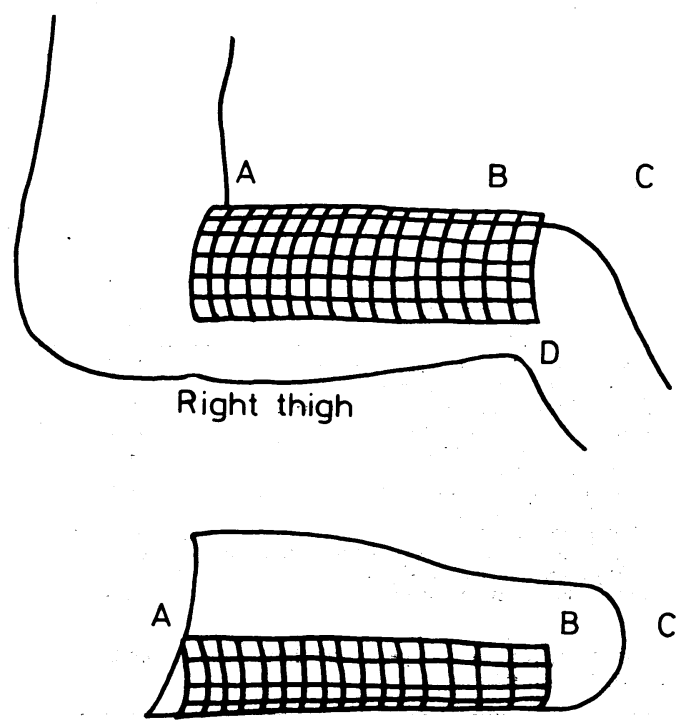

Patient's eye view

How the grid is positioned on upper and outer aspects of thigh. grid (BD) a set number of grid squares from the patella. The pliability of the grid enables it to adapt to the contours of the thigh.

A patient on a twice-daily subcutaneous insulin regimen may, for example, during a sample week, use squares B1-B7 for the morning injections and D1-D7 for the evening injections, the relevant references being recorded in a diary. In this fashion, each square or injection site need be used only once every three months.

\section{Comment}

This simple grid system provides a reasonably accurate method of rotating the insulin injection site. The referencing of each small area of skin also means that injection "squares" found to contain superficial veins or hypersensitive areas can be methodically avoided on further occasions. The grid is both cheap and sufficiently light to be carried in a jacket pocket or handbag.

${ }^{1}$ Lawrence, R D, The Diabetic Life, ed 17th edn, p 116. London, Churchill, 1965.

(Accepted 31 fuly 1979)

West Kirby, Wirral, Merseyside

J O MCGEE, LDS, RCS, dental surgeon

Leicester Royal Infirmary, Leicester LE1 5WW

B P O'MALLEY, MA, MRCP, medical: registrar (present appointment: lecturer in clinical pharmacology, University of Leicester Medical School)

\section{Methyl-cellulose paint possibly causing heart failure}

We report a case of heart failure that may have been caused by inhaling fumes from methyl-cellulose paint.

\section{Case report}

Two weeks before admission a 27 -year-old plumber had been painting a room with methyl-cellulose paint, which is used in the car industry. The paint was in an unmarked container. The room was small and unventilated, and he had been painting for several hours with the door closed. That evening he developed a headache with nausea and vomiting. These symptoms persisted, and then some days later he became short of breath and developed a pressing central chest pain made worse by exertion. He went on to develop orthopnoea and paroxysmal nocturnal dyspnoea. There was no important past history: his health had been perfect. He was a non-smoker, drank little alcohol, and had had no contact with any other known toxins.

On admission he was not feverish, but very breathless and had a regular tachycardia of 130 beats per minute. His blood pressure was $120 / 80 \mathrm{~mm} \mathrm{Hg}$. His jugular venous pressure was raised above the level of the ear lobe in the upright position, and we heard a loud summation gallop. He had no peripheral oedema, but he did have the signs of a right-sided pleural effusion and crepitations throughout both lungs. A chest radiograph showed the effusion and the features of pulmonary oedema and enlargement of the heart (cardiothoracic ratio was $14 / 29 \mathrm{~cm}$ ). His electrocardiogram showed a sinus tachycardia with normal conduction, low voltage complexes, $T$-wave inversion in all leads except V1 and V2, and P-wave inversion in II, III, and aVF.

His congestive cardiac failure was treated with diuretics and bed rest. In the next few days he developed deeper $T$-wave inversion and atrial extrasystoles. He responded well to treatment and 10 days after admission all signs of cardiac failure had gone, and his chest radiograph was returning to normal (cardiothoracic ratio was $12 / 29 \mathrm{~cm}$ ). His electrocardiogram was also improving. He remained in bed for a further month until he was asymptomatic and had a normal chest radiograph (cardiothoracic ratio was $10 / 29 \mathrm{~cm}$ ), but his electrocardiogram remained slightly abnormal. Six months after discharge he was well, taking no medication, and had a normal electrocardiogram. The results of all other investigations were normal including cardiac enzymes, and viral and bacteriological studies on blood and faeces.

\section{Comment}

We think that this patient suffered an acute toxic myocarditis, which so far has not progressed to a chronic cardiomyopathy. Strong circumstantial evidence suggests that the inhalation of paint fumes was the cause, but it is not proved. 